\title{
Application of a flood risk model to the Thames Estuary for economic benefit assessment
}

\author{
B. P. Gouldby ${ }^{1}$, P. B. Sayers ${ }^{1} \&$ O. Tarrant ${ }^{2}$ \\ ${ }^{1}$ Flood Management Group, HR Wallingford, UK \\ ${ }^{2}$ Thames Estuary 2100 Project, Environment Agency, UK
}

\begin{abstract}
The UK Environment Agency is developing a strategic plan for managing flood risk on the Thames Estuary. The flood system is complex, involving flood risk arising from tidal and fluvial sources and the operation and reliability of "active" defence structures such as the Thames Barrier. This is set against the floodplain backdrop that comprises variable topography and high value assets worth over $£ 60$ billion. The plan needs to consider the temporal and spatial changes in flood risk that could occur over the next century. Climate change, in particular rising sea levels, ageing of defence infrastructure and new development in the floodplain can all increase flood risk. A flood risk assessment model of the Thames Flood System has been constructed to quantify the magnitude of this problem. The model includes the potential failure of flood defence structures, a purpose built probabilistic flood spreading method that enables consideration of multiple failures and multiple loading events. These modules are linked into the National Property Database that contains information on the location and type of property in the floodplain, thereby enabling quantification of the economic damages associated with flood events and hence flood risk. The model readily facilitates risk assessment related to asset deterioration, climate change and land use change in the floodplain. This paper details the methods underpinning the flood risk model, and describes how it has been used to assess the performance of a range of flood risk management intervention scenarios, including flood storage as well as new barrier construction, under different climate change scenarios.
\end{abstract}

Keywords: flood, risk analysis, fragility, inundation, damage, economic appraisal. 


\section{Overview of the Thames Estuary flood system}

Flood risk arises on the Thames Estuary from a number of different sources: occurrences of high surges in the North Sea; fluvial flooding on the Thames and fluvial flooding on tributaries of the Thames. By far the greatest potential risk arises from tidal surges and in 1953 such an event caused widespread flooding and damage along the Thames floodplain. To counteract this threat the Thames Barrier and associated defences were constructed, becoming operational in 1982. As well as the Thames Barrier, nine other tidal excluding barriers have been constructed, downstream of the Thames Barrier, where tributaries join the Thames. Forecast and real time data on the tidal conditions in the North Sea are used to ensure these barriers and the Thames Barrier are closed simultaneously, prior to extreme tidal flood events in the Thames Estuary.

There are approximately $280 \mathrm{~km}$ of raised flood defences on the Thames with approximately $200 \mathrm{~km}$ of tributary defences. These static defences vary in type, the most common are earth embankments, steel sheet piled vertical walls and concrete/brick structures. These defences may lie on the actual riverbank or some distance inland. Historically, construction of these linear flood defences along the estuary has been carried out in a reactionary manner to flood events and as such many of the defences (in particular those in central London) show a 'stratigraphy' of raisings that often incorporate a variety of different materials. This means the defences are often fairly complex and composite in nature.

Comprised within the linear static defences are a series of "Frontager floodgates". These have been installed at locations where there is a purposemade 'gap' in the tidal defence walls to allow access to wharfs, jettys and the foreshore, for example. Downriver of the Thames Barrier these are significant in size and have various sealing devices (e.g. rubber flaps, eccentric hinges) and often a telemetry sensor to detect closure states. Upriver of the Thames Barrier they are usually smaller, and some of the openings are closed by damboards. Closure of these gates is often the responsibility of the riparian owners who are notified of flood warnings. "Frontager floodgates" are an integral part of the system. The lack of closure or malfunction of one of them, particularly in the downriver locations, could allow extensive flooding. They are often in remote locations, and being on private frontages are susceptible to unreported damage. An overview of the Thames Flood system is provided in Figure 1.

The present day value of assets within the extreme 1:10,000 floodplain area is in excess of $£ 60$ billion. These assets comprise infrastructure of high national importance such as the houses of parliament and key financial institutions. The economic damage to property alone (i.e. excluding disruption to business, for example) from a single severe event can be in excess of $£ 30$ billion.

In summary, the range of potential flood sources, the variety and spatial scale of flood defence structures and the high value of assets in the floodplain, represent a significant challenge for modelling of the flood risk. 




Figure 1: $\quad$ Overview of the study area.

\section{The flood risk model}

The flood risk model has been described in detail elsewhere (Gouldby et al [1], Environment Agency [2], an overview is provided here for ease of reference.

The model comprises a series of modules that loosely correspond with the Source-Pathway-Receptor-Consequence (SPRC) conceptual model of the flood system, HR Wallingford [3]. The model components include: extreme value distributions of water levels along the length of the Thames Estuary and tributaries (Source component); fragility curves to represent the performance of the fixed defences as well as the active barriers and "Frontager floodgates" (Pathway); a hydraulic flood spreading model to represent the propagation of floodwater across the floodplain (Pathway) and the National Property Database (Receptor) allied to economic depth/damage functions (Consequence (PenningRowsell et al [4])), to quantify the consequences of flooding.

Within the model domain, the study area floodplain is resolved into discrete flood areas. These areas are assumed to be hydraulically independent of one another, with boundaries typically formed from topographical features, high ground or river channels (i.e. tributaries), for example. The system of linear defences forms a boundary between the river channel and the floodplain area. The defence system comprises discrete lengths of defence sections that vary in type (e.g. embankment, sheet pile wall, "Frontager floodgates"), condition or geometry and therefore resistance to flood loading. The lengths of the defence sections are naturally limited to $600 \mathrm{~m}$ for soft defences (embankments) and 
$300 \mathrm{~m}$ for hard defences (sheet pile walls). Within any flood area, the likelihood of an extreme hydraulic load on the defence system is assumed to be dependent. The performance (structural integrity) of individual defences, in response to the hydraulic loading, is assumed to be independent.

The state of each defence section, failed or not failed, $\left(d_{i}, \bar{d}_{i}\right)$ on any specified extreme hydraulic loading event, can significantly influence the quantity of water discharged into the flood area, and hence subsequent damage. The probability mass function for the random variable of the defence system state $D$, conditional on the random variable for the hydraulic loading $(L)$ can be given by equation 1 :

$$
p_{D \mid L}(d, l)=\prod_{i=1}^{k} p\left(d_{i} \mid l\right) \prod_{i=k+1}^{n}\left[1-p\left(\bar{d}_{i} \mid l\right)\right]
$$

where $n$ denotes the total number of defences in the defence system and $k$ represents the number of failed defences. As $n$ can exceed 100, the number of possible defence system states is large (i.e. $>2^{100}$ ) and it is impractical to evaluate the flood damage associated with all of the possible combinations over a wide range of loading conditions, a Monte-Carlo simulation procedure is therefore employed. The hydraulic loading variable $(L)$ is discretised into a series of $q$ levels $\left(l_{i}, l_{i+1 .} . l_{q}\right)$. Under each loading level, the defence system states are sampled, with reference to the fragility curves, and the economic damage evaluated through the activation of the flood spreading model and damage functions. The number, $m$, of defence system state samples required for each loading level is monitored using pre-defined criteria for convergence on the risk (Equation 2):

$$
R=\sum_{i=2}^{q-1}\left[\left[p\left(L \geq \frac{l_{i}+l_{i+1}}{2}\right)-p\left(L \geq \frac{l_{i}+l_{i-1}}{2}\right)\right] \frac{1}{m_{i}} \sum_{j=1}^{m_{i}} c_{j}\right]
$$

The primary outputs of the model are the spatial variation in flood risk, expressed as Expected Annual Damage (EAD), and the spatial variation in inundation likelihood, expressed as the annual probability of exceeding $0 \mathrm{~m}$ flood depth.

\section{Management interventions and their model representation}

\subsection{Overview of the management options}

The TE2100 Project is developing a strategic flood risk management plan of the estuary system over the coming century. A primary element of this strategy is the economic appraisal of different system interventions, including prescribed policies and management options. The development of the plan is ongoing (due for dissemination in December 2009). The flood risk analysis model has been used in a preliminary investigation of the benefits of some potential risk management options that have subsequently been used in benefit cost analysis in support of a wider decision-making process. In this paper, sample results of the benefit analysis are provided from a range of policies and options. 
The pro-active management of flood risk promoted by the Environment Agency, and adopted within TE2100 sees a number of timed interventions, each seeking to manage risk within an acceptable zone. This concept recognises that risk is set to increase in the future as the drivers for change (climate change, continued development in floodplain and asset deterioration) all act on the system to increase risk. However, through the implementation of risk management options at different points through out the century, the risk can be managed within acceptable bounds. The upper and lower limits of this zone of acceptability can be defined in terms of costs and benefits along with possible social and environmental impacts. At a high level, the acceptability of risk in different areas of the estuary is explored through the analysis of specific flood risk management polices. These policies then provide a framework against which flood risk management options can be developed and appraised.

A definition of the core management policies is provided in Table 1. The P1 Policy is regarded as the baseline or "do nothing" case, against which the other inventions are compared to determine the intervention benefit.

Table 1: $\quad$ Policy definitions.

\begin{tabular}{|l|l|}
\hline $\begin{array}{l}\text { Policy } \\
\text { Number }\end{array}$ & \multicolumn{1}{|c|}{ Policy definition } \\
\hline P1 & $\begin{array}{l}\text { No active intervention (including flood warning and maintenance), } \\
\text { continue to monitor and advise }\end{array}$ \\
\hline P2 & $\begin{array}{l}\text { Reduce existing flood risk management actions (accepting that flood risk } \\
\text { will increase with time) }\end{array}$ \\
\hline P3 & $\begin{array}{l}\text { Continue with existing and alternative actions to manage flood risk at the } \\
\text { current level (accepting that flood risk will increase over time from this } \\
\text { baseline) }\end{array}$ \\
\hline P4 & $\begin{array}{l}\text { Take further action to sustain the current level of flood risk into the } \\
\text { future (responding to the potential increases in risk from urban } \\
\text { development, land use change and climate change) }\end{array}$ \\
\hline P5 & \begin{tabular}{l} 
Take further action to reduce flood risk (now and/or in the future) \\
\hline
\end{tabular} \\
\hline
\end{tabular}

Whilst a range of management options have been developed, this paper focuses on two: High Level Option (HLO) 1 and HLO2. These interventions are made at specified future points in time. Table 2 summarises the intervention actions, including future date, for HLO 1 and 2. The main difference between the two options is the introduction of flood storage systems in the outer estuary. These systems reduce the volume of water propagating upstream and therefore reduce the loading on upstream defences.

The interventions are being assessed against a range of climate change scenarios. These scenarios are referred to as: Defra (using the current guidance for England and Wales); Medium High (based on a Medium High emissions scenarios, Hulme et al [5]) and High + (based on an emissions scenario more extreme than High, Hulme et al [5]). 
Table 2: $\quad$ Description of the HLO interventions.

\begin{tabular}{|c|c|}
\hline Epoch & Intervention action \\
\hline \multicolumn{2}{|r|}{ HLO 1} \\
\hline 2040 & $\begin{array}{ll}\text { - } & \text { re-profile channel navigation channel (West London) } \\
\text { - } & \text { managed retreat, in the Outer Estuary } \\
\text { - } & \text { Outer Estuary defences raised by } 0.3 \mathrm{~m}\end{array}$ \\
\hline 2070 & $\begin{array}{ll}\text { - } & \text { Managed retreat in the Outer Estuary } \\
\text { - } & \text { Over-rotate the Thames Barrier, reduces upstream loads } \\
\text { - } & \text { Defences raised by } 0.5 \mathrm{~m} \\
\text { - } & \text { Some new defences }\end{array}$ \\
\hline 2085 & - $\quad$ Restore interim defences upstream of the Thames Barrier \\
\hline \multicolumn{2}{|r|}{ HLO 2} \\
\hline 2040 & $\begin{array}{ll}\text { - } & \text { re-profile channel navigation channel (West London) } \\
\text { - } & \text { managed retreat, in the Outer Estuary } \\
\text { - } & \text { Defences raised by } 0.3 \mathrm{~m}\end{array}$ \\
\hline 2070 & $\begin{array}{ll}\text { - } & \text { managed retreat in the Outer Estuary } \\
\text { - } & \text { flood storage areas } \\
\text { - } & \text { over-rotate the Thames Barrier } \\
\text { - } & \text { Defences raised by } 0.3 \mathrm{~m} \\
& \text { Some new defences, including managed retreat }\end{array}$ \\
\hline 2085 & - $\quad$ Restore interim defences upstream of the Thames Barrier \\
\hline
\end{tabular}

\subsection{Representation of the options within the risk model}

The risk model is capable of representing a wide range of changes to the flood system, through modification of the various $S P R C$ modules. This enables the performance of management policies or intervention actions to be assessed in terms of risk, or more specifically benefit (risk reduction), when the risk achieved under the intervention is compared to the baseline ("do nothing"). For example, different climate change scenarios can be reflected through modification to the extreme hydraulic loads on the system (Source). The deterioration of defences is reflected through modifications to the fragility curves of the defence sections (Pathway). Different rates of deterioration occur under the "do nothing" scenario, as opposed to a routine maintenance scenario, for example. These rates of deterioration are explicitly reflected through the fragility curve modifications. Specific modifications to the existing defences, such as raising crest levels, are incorporated by modifying the model databases of the defences. More complex interventions, such as the introduction of flood storage areas in the outer estuary, are incorporated by modifying the spatial boundary of the defence line, accompanied by a reduction in the upstream hydraulic loads. Socio-economic changes to the flood system, such as increased development in the floodplain can be explicitly included by modifying the receptor databases that comprise depth damage relationships based on the type and number of different properties. 
The models have been run for a range of policies and management intervention scenarios, over the 100 year appraisal period. Typically four epochs are modelled for a given intervention and climate change scenario. Some sample results from this analysis are presented below.

\section{Results}

Figure 2 shows some sample results for the P3 policy (routine maintenance). The Present Day risk is low at $<£ 5 \mathrm{~m}$, reflecting the high degree of protection afforded by the existing system. The barriers and the existing defences, with crest levels set higher than a nominal 1000 year water level, restrict significant damages occurring in flood events with greater than 2000 year return periods. Under an intervention scenario whereby the state of the defences and the reliability of the barriers are assumed to be maintained at present day levels, the annual risk increases to $£ 55 \mathrm{~m}$ in the year 2100 , if the UK recommended allowance for climate change is realised. This is more than an order of magnitude higher than the Present Day. If however, a more extreme climate change scenario is assumed, the risk can rise to almost two orders of magnitude higher than the Present Day. It is therefore evident that there is potential economic justification for implementing a risk management plan to mitigate this increase in risk.

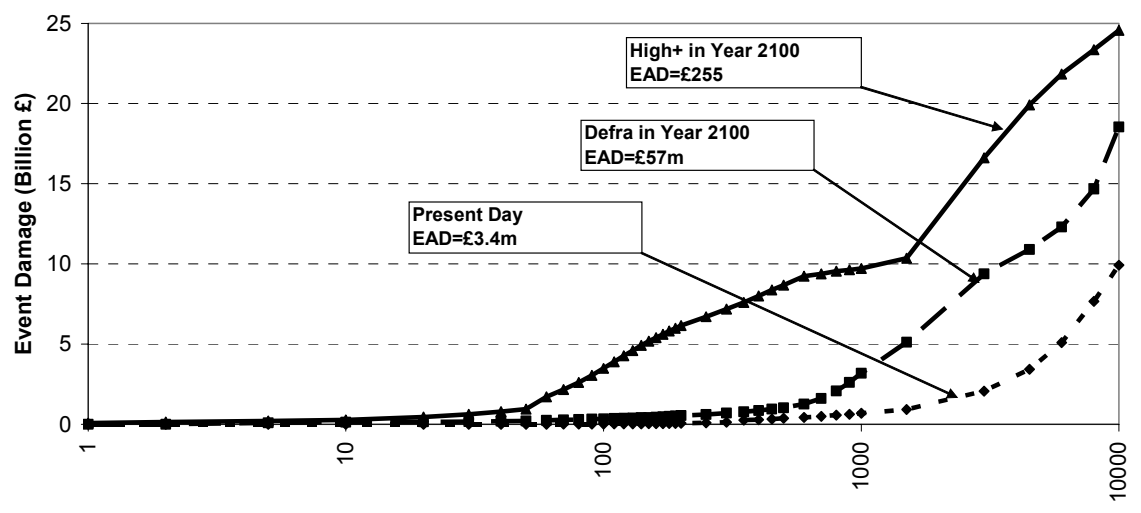

Return Period (Years)

Figure 2: $\quad$ Return period damages for the Thames system under a P3 policy.

Figure 3 shows the risk profile through time of the P3 policy and HLO 2 under the Defra climate change scenario. There is little difference in risk profile between the two intervention scenarios until the middle of the century, where a divergence occurs. Under the P3 Policy, the EAD increases significantly when compared to the HLO 2, and by the end of the century the difference in risk under the P3 policy has risen to around a factor of 5 higher than the HLO 2. Closer inspection of the model results has shown that over $90 \%$ of the difference in risk profile, in this climate change scenario, can be attributed to a significant 
increase in risk in the Outer Estuary. This increase is due to the lower (than those upstream) defences in the outer estuary and the amount of sea level rise that occurs under the Defra climate change scenario. In the light of this result there may be merit in modifying the HLO 2 to address the potential issue of increased risk in the outer estuary. Further investigation is required, however, to establish whether this pattern is observed under continued floodplain development (i.e. the Thames Gateway (http:/www.thamesgateway.gov.uk/) and different climate change scenarios.



Figure 3: Change in risk through time, under the Defra climate change scenario.

\section{Conclusions}

The Thames flood system is complex, comprising hydraulic loading from different sources, a range of static and active defence structures and high value assets located on specific parts of the floodplain. A sophisticated flood risk analysis model, capable of handling this complexity has been developed and applied to assess the risk associated with a range of intervention policies and options. The model can reflect changes that arise within the system as a result of, for example, climate change, different defence maintenance and capital refurbishment strategies and floodplain development scenarios.

The reduction in risk that arises for any given intervention strategy, when compared against a "do nothing" scenario, can be used to derive the economic benefit of the specific strategy. These benefits can be utilised within a benefit cost analysis to establish the economic justification (or not) of the proposed management strategy. The model can be used in an iterative capacity to help develop and refine options. 
The preliminary results presented in this paper suggest that a risk profile there may be merit in modifying the HLO 2 to address the potential for increase in risk in the outer estuary. Further investigation is required, however, to establish whether this pattern is observed under continued floodplain development (i.e. the Thames Gateway (http://www.thamesgateway.gov.uk/) and different climate change scenarios.

\section{Acknowledgements}

This work was funded by the Thames Estuary 2100 Project of the Environment Agency, the FLOODsite Project commissioned under the European Union's $6^{\text {th }}$ Framework, the joint Defra/Agency research programme (Performance-based Asset Management) and RPA 4 of the Flood Risk Management Research Consortium, with funding led by EPSRC and the Environment Agency. The authors are grateful for the support and advice received from Dr. Mervyn Bramley (Independent consultant), and Dr. Chrissy Mitchell (Environment Agency)

\section{References}

[1] Gouldby, B, Sayers P, Mulet-Marti J, Hassan M and Benwell D., A methodology for regional-scale flood risk assessment. Proceedings of the Institution of Civil Engineers, Water Management, accepted for publication, 2008.

[2] Environment Agency - TE2100. Performance based asset management: System analysis model V3. HR Wallingford Technical Report IA8/10

[3] HR Wallingford, Risk performance and uncertainty in flood and coastal defence: A review. FD2302/TR1, Environment Agency. HR Wallingford Report SR 587, 2002.

[4] Penning-Rowsell, E, Johnson C, Tunstall S, Tapsell S, Morris J, Chatterton J and Green C, Eds. The Benefits of Flood and Coastal Risk Management: A manual of assessment techniques, Middlesex University Flood Hazard Research Centre, 2005.

[5] Hulme, M, Jenkins G.J, Lu X., Turnpenny J.R., Mitchell T.D., Jones R.G., Lowe J., Murphy J.M., Hassell D., Boorman P., McDonald R. and Hill S., Climate change Scenarios for the United Kingdom: the UKCIP02 scientific report. UK Climate Impacts Programme, (2002). 